\title{
LAS DECLINACIONES DE LA SUBSIDIARIEDAD EN EL DERECHO CONSTITUCIONAL ITALIANO*
}

\author{
ANTONIO D'ATENA
}




\section{SUMARIO}

1. LA DIMENSIÓN ÉTICO-POLÍTICA Y LA DIMENSIÓN JURÍDICOCONSTITUCIONAL DEL PRINCIPIO. 2. LA DECISIÓN DE PREFERENCIA EN FAVOR DEL NIVEL MÁS CERCANO. 3. LAS RAÍCES DE LA PREFERENCIA. 4. LA DECLINACIÓN VERTICAL Y LA DECLINACIÓN HORIZONTAL DEL PRINCIPIO. 5. LA DISCIPLINA CONSTITUCIONAL ITALIANA. 6. EL ARTÍCULO 118 APARTADO 1: EL PRINCIPIO DE SUBSIDIARIEDAD VERTICAL. 7. EL ARTÍCULO 118 APARTADO 4: EL PRINCIPIO DE SUBSIDIARIEDAD HORIZONTAL. 7.1. Subsidiariedad horizontal y operaciones in house. 7.2. Las lecturas desvalorizadoras del art. 118 apartado 4: crítica. 7.3. La lectura «fuerte» del art. 118 apartado final: a) con referencia a las relaciones público-privadas (analogía con la disciplina de numerosas Gemeindeordnungen alemanas). 7.4. Sigue: b) con referencia a las relaciones entre las autonomías territoriales y las autonomías funcionales. 


\title{
LAS DECLINACIONES DE LA SUBSIDIARIEDAD EN EL DERECHO CONSTITUCIONAL ITALIANO*
}

\author{
POR \\ ANTONIO D'ATENA \\ Catedrático de Derecho Constitucional \\ Università di Roma Tor Vergata
}

\section{LA DIMENSIÓN ÉTICO-POLÍTICA Y LA DIMENSIÓN JURÍDICO-CONSTITUCIONAL DEL PRINCIPIO}

Lo primero que llama la atención a quien se ocupa del principio de subsidiariedad se encuentra en la marcada tensión entra las dos dimensiones en él presentes: la dimensión ético-política y la dimensión jurídico-constitucional.

Desde un punto de vista ético-político, éste se presenta como un principio riquísimo, comparable, gracias a su fuerza disruptiva al principio de la separación de poderes en el momento de su primera aparición histórica ${ }^{1}$. En cambio, si nos colocamos en el terreno jurídico-constitucional, no puede sino constatarse la dificultad de dar a los enunciados en que se manifiesta un alcance apreciable prescriptivamente; con el riesgo, lejano de ser sólo teórico, de la heterogeneidad de las finalidades.

* Traducción de Martín Loo Gutiérrez, doctorando en derecho público en la Università di Roma Tor Vergata.

1 Así: D’ATENA, Il principio di sussidiarietà nella Costituzione italiana, en Rivista italiana di diritto pubblico comunitario, 1997, p. 627 (así como en Id., L'Italia verso il «federalismo». Taccuini di viaggio, Milano, 2001, p. 343). 
Pueden recordarse, sobre este punto, los trabajos de un congreso llevado a cabo en Milán, en diciembre de 1992, promovido por la Asociación Italiana de Constitucionalistas ${ }^{2}$, en el curso del cual, frecuentemente se subrayó cómo la positivización del principio por parte del Tratado de Maastricht arriesgara de dar vida a resultados opuestos a aquellos perseguidos por parte de los Estados miembros. Se señalaba, de hecho, que el art. $3 \mathrm{~b}$ (hoy, art. 5 TUE), permitiendo a la Comunidad de intervenir en ámbitos de competencia de los Estados, la habría dotado de una auténtica competencia de la competencia. De este modo se comprende la difusa preocupación acerca de que el principio introducido en el Tratado, en función de tutela de los niveles institucionales inferiores, pudiera manifestarse en perjuicio de éstos.

Es ésta la razón por la cual el principio de subsidiariedad constituye un desafío particularmente complejo, tanto para el legislador, como para los constitucionalistas.

Distinto sería el discurso, obviamente, si se adhiriera a las lecturas desvalorizadoras del principio, las cuales, sobretodo en un comienzo, tuvieron gran difusión en el debate político institucional que se produjo en toda Europa.

La referencia se hace, principalmente, a las lecturas totalmente desvalorizadoras. Según ellas, el principio se encontraría desprovisto de toda consistencia, resolviéndose en vacío gobbledegook, para retomar la expresión onomatopéyica desdeñósamente utilizada en la época por la señora Tatcher: una expresión equivalente a nuestro bla bla bla.

Asimismo, consideraciones fundamentalmente similares deberían valer, en el caso fueran acogidas las lecturas parcialmente desvalorizadoras del principio. Estas lecturas no discuten la consistencia del principio sino que su autonomía y alcance innovador. De acuerdo con ellas, las enunciaciones positivas del principio de subsidiariedad se limitarían a expresar la obvia exigencia de que las funciones sean entregadas al nivel más idóneo para ejercitarlas. Ellas, por tanto, de un lado no harían que expresar criterios descontados de racionalidad organizativa $y$, de otro, presentarían un valor principalmente eficientístico, recayendo en un área normalmente cubierta por otros principios: en Italia, por el principio del buen funcionamiento de la Administración, al que se refiere el art. 97, apartado 1 , de la Constitución italiana.

Se trata, no obstante, de lecturas que no pueden ser compartidas.

${ }^{2}$ Las actas del congreso fueron publicadas el año 1995: ASSOCIAZIONE ITALIANA DEI COSTITUZIONALISTI, Le prospettive dell'Unione europea e la Costituzione, Padova, 1995. 


\section{LA DECISIÓN DE PREFERENCIA EN FAVOR DEL NIVEL MÁS CERCANO}

A la primera se opone la circunstancia que, como demuestra la experiencia de los ordenamientos en los cuales el principio de subsidiariedad ha encontrado adecuadas traducciones normativas (y, como veremos, entre ellas la del ordenamiento italiano), su presencia es todo menos que irrelevante. De ella, en efecto, fluyen consecuencias jurídicas dotadas de una consistencia difícilmente controvertible.

La segunda lectura, por su lado, deja escapar el sustrato axiológico del principio de subsidiariedad. El cual se funda en una elección de valor muy precisa: la decisión de preferencia en favor del nivel más cercano a los interesados ${ }^{3}$.

$\mathrm{Si}$ se considera este elemento, se constata fácilmente que un principio de esta clase es todo menos que descontado.

Se piense, por ejemplo, al planteamiento - no carente de seguidores en la reflexión estadounidense sobre el federalismo- según el cual el nivel de la intervención sería, después de todo, indiferente: lo que cuenta no es tanto quién decide sino cómo se decide (o, en otros términos, el contenido y no el autor de la decisión $)^{4}$.

Se piense, además, en los partidarios de la antisubsidiariedad, quienes se hacen portadores de una decisión de preferencia opuesta a aquella que se encuentra en la base del principio de subsidiariedad. Según su opinión, de hecho, el ni-

${ }^{3}$ En propósito, especialmente, ISENSEE, Subsidiaritätsprinzip und Verfassungsrecht. Eine Studie über das Regulativ des Verhältnisses von Staat und Gesellschaft, Berlin, 1968, pp. 226, 314; HÄBERLE, Das Prinzip der Subsidiarität aus der Sicht der vergleichenden Verfassungslehre, en Archiv des öffentliches Recht (AöR), 1993, pp. 186 y ss.; LANGER, Subsidiarität und Anerkennungsprinzip en Zeitschrift für Gesetzgebung (ZG), 1993, p. 196. Además: STEIN, Subsidiarität als Rechtsprinzip?, en MERTEN (editor), Die Subsidiarität Europas, Berlin, 1993, p. 40; RIDOLA, Das Prinzip der Subsidiarität im Regionalstaat. Die Beispiele Spaniens und Italiens: eine kritische Würdigung, en RIKLIN/BATLINER (editores), Subsidiarität. Ein interdisziplinares Symposium, Vaduz 1994, p. 351; D'ATENA, Das Subsidiaritätsprinzip in der italienischen Verfassung, in NETTESHEIM/SCHIERA (editores), Der integrierte Staat, Berlin 1999, 108; Id., Il principio di sussidiarietà nella Costituzione italiana, en L'Italia verso il «federalismo». Taccuini di viaggio, cit., pp. 319 y ss.; Id., Die Subsidiarität: Werte und Regeln, in BLANKENAGEL/PERNICE/SCHÜLZE-FIELITZ (editores), Verfassung im Diskurs der Welt. Liber Amicorum für Peter Häberle zum siebzigsten Geburtstag, Tübingen, 2004.

${ }^{4}$ En este sentido: KINSLEY, The Case Against the States, en Time Magazine, 16/1995, p. 78, citado y criticado por BERMANN, Harmonization and Regulatory Federalism, en PERNICE (editor), Harmonization of Legislation in Federal Systems, Constitutional, Federal and Subsidiarity Aspects - The European Union and the United States of America Compared (First Symposion of the Columbia Law School and the Law Faculty of the Johann Wolfgang Goethe-University Frankfurt), Baden-Baden, 1996, pp. 37 y ss.

(C) UNED. Revista de Derecho Politico

N. ${ }^{\circ} 79$, septiembre-diciembre 2010, págs. 255-284 
vel que se debe preferir sería el nivel central, en el cual debería presumirse una mayor eficiencia. Quien se coloca en esta posición subraya — por ejemplo- que las decisiones del centro permiten economías de escalas e igualaciones fuera del alcance de los niveles locales 5 .

No se debe, finalmente, olvidar que la Historia ofrece ejemplos de procesos de tipo federal que, por largos períodos de su evolución, se desarrollaron de modo fundamentalmente antisubsidiario. Esto sucedió, además del caso del federalismo norteamericano, en el proceso de integración europea, inspirada, hasta el Tratado de Maastricht, en una filosofía fundamentalmente centralista ${ }^{6}$.

\section{LAS RAÍCES DE LA PREFERENCIA}

Las raíces de la decisión de preferencia que constituye el centro del principio de subsidiariedad (la preferencia - como se ha dicho- en favor del nivel más cercano) son múltiples. Simplificando, pueden indicarse las tres principales.

La primera se encuentra constituida por la Doctrina Social de la Iglesia. Nos referimos, en particular, a la Encíclica Quadragesimo Anno de 1931, que coloca en la base del principio el primado ético de la persona con respecto al Estado 7 . Una

${ }^{5}$ Consideraciones en esta línea se leen, por ejemplo, en AA.VV., Making Sense of Subsidiarity: How Much Centralization for Europe? Monitoring European Integration 4 (Annual report, 1993 del Centre of Economic Policy Research - CEPR), pp. 36 y ss.

${ }^{6}$ Sobre el punto: D'ATENA, Sussidiarietà e sovranità, en La costituzione europea (Annuario 1999 dell'Associazione italiana dei costituzionalisti - AIC), Padova 2000, pp. 17 y ss.; Id., Subsidiarity and Division of Competencies between European Union, its Member States and their Regions en PERNICE/MICCU (editores), The European Constitution in the Making, Baden-Baden, 2003. Además, últimamente: MOSCARINI, A., Competenza e sussidiarietà nel sistema delle fonti. Contributo allo studio dei criteri ordinatori del sistema delle fonti, Padova 2003, 220 ss. (así como sobre el camino de la subsidiariedad en la evolución anterior a Maastricht: pp. 55 y ss.).

7 Estos, los pasajes pertinentes: «como no se puede quitar a los individuos y dar a la comunidad lo que ellos pueden realizar con su propio esfuerzo e industria, así tampoco es justo, constituyendo un grave perjuicio y perturbación del recto orden, quitar a las comunidades menores e inferiores lo que ellas pueden hacer y proporcionar y dárselo a una sociedad mayor y más elevada, ya que toda acción de la sociedad, por su propia fuerza y naturaleza, debe prestar ayuda a los miembros del cuerpo social, pero no destruirlos y absorberlos.» Sobre el significado, incluso constitucional, de estos enunciados, cfr.: MERKL, Der staatsrechtliche Gehalt der Enzyklika "Quadragesimo Anno", en Zeitschrift für öffentliches Recht (ZöR), 1934, pp. 208 y ss. (hoy en la antología titulada: Die Wiener rechtstheoretische Schule. Schriften von Hans Kelsen, AdolfMerkl, Alfred Ross, Wien-Frankfurt-Zürich-Salzburg-München, sine data, pp. 381 y ss., spec. pp. 384 y ss.); KARRER, Il principio di sussidiarietà nella Chiesa, in BARAUNA (editor), La Chiesa del Vaticano II, Firenze 1966, pp. 589 y ss.; BEYER, Principe de subsidiarité ou «juste autonomie» dans l'Eglise, en 
primacía, cuya afirmación presentaba un alcance decisivamente revolucionario en el momento histórico en el cual la Encíclica hizo aparición: la época de los grandes totalitarismos del Novecientos europeo, de los totalitarismos existentes y de los totalitarismos anunciados, los cuales - como todos los totalitarismos- no sustraían ninguna esfera a la presencia invasiva del Estado. De aquí la fuerza disruptiva de una concepción que llamaba a los poderes públicos a «ayudar en modo supletorio los miembros del cuerpo social» y no a «destruirlos y absorberlos».

La segunda raíz del principio de subsidiariedad puede ser identificada con la tradición liberal ${ }^{8}$, que coloca como base de aquél el valor de la libertad humana.

Entre las enunciaciones más antiguas de este planteamiento se encuentran algunas frases de la correspondencia de Thomas Jefferson, que se hacen notar a causa de su cristalina claridad. En una carta dirigida a Joseph C. Cabell el 2 de febrero de 1816, en particular, se lee que cada hombre debe ser depositario de los poderes que es capaz de ejercitar directamente y que en las relaciones entre los individuos y las instituciones, así como entre instituciones de niveles distintos, la intervención del nivel superior se justifica solamente si se encuentra orientado a hacer frente a la inadecuación del nivel inferior, en una escala que va desde la granja a la gran República nacional?

Nouv. Rev.T héol., 1986, pp. 801 y ss.; ISENSEE, Subsidiaritätsprinzip und Verfassungsrecht, cit., pp. 18 y ss.; HÄBERLE, Subsidiarität aus der Sicht der vergleichenden Verfassungslehre, in RIKLIN/BATLINER (editores), Subsidiarität. Ein interdisziplinares Symposium, cit., pp. 292 y ss.; HÖFFE, Subsidiarität als staatsphilosophisches Prinzip?, ibidem, pp. 24 y ss.; BUTTIGLIONE, Eine philosophische Interpretation des sozialethischen Prinzips der Subsidiarität, ibidem, pp. 56 y ss.; STADLER, Subsidiaritätsprinzip und Föderalismus. Ein Beitrag zum schweizerischen Staatsrecht, Freiburg i.d.S. 1951, pp. 9 y ss.; LECHELER, Das Subsidiaritätsprinzip. Strukturprinzip einer europäischen Union, Berlin, 1993, pp. 29 y ss. A las anticipaciones contenidas en la Rerum Novarum de 1891 y a los desarrollos a los que se refiere la Centesimus Annus hace oportunamente referencia, MOSCARINI, A., Competenza e sussidiarietà nel sistema delle fonti. Contributo allo studio dei criteri ordinatori del sistema delle fonti, cit., pp. 20 y ss., not. 14.

${ }^{8}$ Sobre este punto, v. la síntesis de LECHELER, Das Subsidiaritätsprinzip. Strukturprinzip einer europäischen Union, cit., pp. 33 y ss.

9 JEFFERSON, Il decentramento del potere, en AQUARONE (editor), Antologia degli scritti politici di Thomas Jefferson, Bologna, 1961, p. 109: «E dividendo e suddividendo la grande repubblica nazionale in queste repubbliche minori da un estremo all'altro della gerarchia, finché si giunga all'amministrazione da parte di ciascuno individuo della propria fattoria; attribuendo ad ognuno la direzione di ciò che il suo occhio riesce a sorvegliare direttamente, che tutto verrà realizzato per il meglio. [...] Io sono convinto che, se l'Onnipotente non ha decretato che l'uomo non debba mai essere libero (e sarebbe bestemmia il crederlo), si scoprirà che il segreto consiste nel farsi egli stesso depositario dei poteri che si riferiscono a lui, nella misura in cui è capace di esercitarli, e nel delegare soltanto quelli che sono ad di là delle sue capacità, mediante un processo sintetico, a gradi sempre più elevati di funzionari, in modo da conferire sempre meno poteri a mano a mano che i delegati rappresentano sempre più un'oligarchia». 
Uno de los temas que esta tradición toca es aquél de las relaciones entre Estado y Mercado. De esta manera, configurándose la iniciativa económica privada como un corolario de la libertad que corresponde a todos los hombres, el Estado no debería restringir sus manifestaciones ${ }^{10}$. El Estado, en lo específico, se encontraría legitimado a intervenir en el mercado, solamente cuando ello sea requerido por la exigencia de garantizar condiciones de libre competencia o, en cualquier caso, de hacer frente a la inadecuación del mismo mercado (es decir, en las situaciones en que este último no sea capaz de satisfacer eficazmente exigencias merecedoras de tutela $)^{11}$.

La tercera raíz, finamente, se encuentra constituida por la reflexión europea sobre el federalismo.

Ésta reconduce el principio a dos distintas rationes.

La primera es una ratio de tipo garantística. En los ordenamientos federales, de hecho, a la división de poderes comúnmente entendida —es decir, que opera en términos horizontales al interior del Estado-persona- se suma una división de tipo vertical, que opera en las relaciones entre entes territoriales de distinto nivel, la que pasa a enriquecer el principio con una dimensión adicional, incrementando, de este modo, sus potencialidades garantísticas ${ }^{12}$.

Es ésta, entre otras, la razón de la incompatibilidad, incluso ontológica, entre el federalismo y los regímenes totalitarios. No es una casualidad, por ejemplo, que una de las primeras reformas institucionales del nacionalsocialismo haya consistido en la cancelación de la estructura federal la cual se remontaba a la Constitución bismarckiana del 1871 y que fuera confirmada

10 Sobre el argumento, v., en la literatura constitucional italiana: MOSCARINI, A., Sussidiarietà e libertà economiche, en MODUGNO (editor), Trasformazioni della funzione legislativa, Milano, 1999, pp. 245 y ss.

${ }^{11}$ Información con referencia específica a los ordoliberales de Freiburg se encuentra en ISENSEE, Subsidiaritätsprinzip und Verfassungsrecht, cit., pp. 137 y ss.

${ }_{12}$ El uso del modelo se encuentra muy difundido. A título meramente ejemplar, cfr.: WEBER, W., Spannungen und Kräfte im westdeutschen Verfassungssystem, Stuttgart, 1958, pp. 26 y ss.; KÄGI, Selbstbestimmung und Mitverantwortung. Zur Kernfrage des Föderalismus, en Föderalismus in der heutigen Welt, Sonderheft de los Schweizer Monatshefte, 1959, pp. 687 y ss.; ISENSEE, Subsidiaritätsprinzip und Verfassungsrecht, cit., p. 135 (y las referencias ahí indicadas), p. 237; HÄBERLE, Das Prinzip der Subsidiarität aus der Sicht der vergleichenden Verfassungslehre, en AöR, 1993, pp. 186 y ss.; EMILIOU, Subsidiarity: An Effective Barrier Against «the Enterprises of Ambition"?, en Eur.opean Law Review, 1992, pp. 386 y ss.; DREIER, Grundlagen und Grundzügen staatlichen Verfassungsrechts: Deutschland, en V. BOGDANDY/CRUZ VILLALÓN/HUBER (editores), Handbuch Ius Publicum Europaeum, I, Heidelberg, 2007, pp. 58 y ss. Para una lectura, en la misma clave, del regionalismo italiano, reflexiones de gran interés se pueden encontrar en BARDUSCO, Lo Stato regionale italiano, Milano, 1980, pp. 209 y ss. 
por la Constitución de Weimar del $1919^{13}$. Como no es una casualidad que, inmediatamente después de la guerra, las fuerzas aleadas, para evitar nuevas involuciones de tipo totalitario, hayan ejercido presiones sobre Alemania para que restableciera, como efectivamente sucedió, la estructura federal del Estado $^{14}$.

Con esto no entendemos afirmar que en todos los ordenamientos federales, el reparto de las competencias entre centro y periferias se encuentre informada por el principio de subsidiariedad (es sabido, por ejemplo, que una afirmación de este tipo no es válida para el ordenamiento federal norteamericano). Se pretende afirmar una cosa distinta: que en los ordenamientos federales que construyen la estructura de las competencias basados en el principio de subsidiariedad, el alcance garantístico de la división vertical de los poderes (comunes a todos los ordenamientos federales, de manera indistinta) resulta potenciada gracias al tendencial reconocimiento a los niveles periféricos de todas las competencias que son capaces de ejercitar.

La segunda ratio que la reflexión sobre el federalismo coloca a la base del principio de subsidiariedad es de tipo democrático. Se subraya, en particular, que la posibilidad de participación de los ciudadanos a la elaboración de las decisiones que les atañen y al control de las instancias que los representan, sean directamente proporcionales a la proximidad del nivel de gobierno presentando, por ende, la máxima intensidad en los niveles que sean a ellos más cercanos $^{15}$.

Este planteamiento constituye — por ejemplo— la transparente inspiración de la Carta Europea de Autonomía Local, suscrita en Estrasburgo, en el ámbito del Consejo de Europa, el 15 de octubre de 1985 y hecha ejecutiva en Italia con la ley número 439/1989. Tal acto, no solamente enuncia con absoluta claridad la

${ }^{13}$ Nos referimos a la ley de 30 enero de 1934 (Neuaufbau-Gesetz), la cual eliminó las representación popular de los Länder (art. 1), transfirió al Reich los derechos de soberanía (Hoheitsrechte) sobre éstos (art. 2) y subordinó jerárquicamente sus gobiernos al Gobierno central (art. 3). El último residuo de estructura federal —el Reichsrat — fue suprimido quince días después con la ley del 14 de febrero de 1934 (Gesetz über die Aufhebung des Reichsrats).

${ }_{14}$ Acerca de la diversidad de opiniones existentes entre los Aleados sobre el punto en la época de la Conferencia de Moscú de marzo de 1947, v.: GREWE, Antinomien des Föderalismus, Schloss Bleckede a.d. Elbe, 1948, pp. 11 y ss. En general, sobre el caso v., resumidamente: RENZSCH, Il federalismo tedesco in prospettiva storica: federalismo come succedaneo dello Stato nazionale, en MIGLIO (editor), Federalismi falsi e degenerati, Milano, 1997, pp. 11 y ss.

${ }^{15}$ Así, entre otros: STADLER, Subsidiaritätsprinzip und Föderalismus. Ein Beitrag zum schweizerischen Staatsrecht, cit., p. 161; FLEINER-GERSTER, Die Gemeindeautonomie, der Föderalismus und das Prinzip der Subsidiarität, en RIKLIN/BATLINER (editores), Subsidiarität, cit., pp. 337 y ss. 
decisión de preferencia en favor de los entes locales ${ }^{16}$, sino que reconduce expresamente tal elección al nivel de democraticidad que estos muestran ${ }^{17}$.

Más allá de las diferencias no baladíes apenas delineadas, todas las corrientes reseñadas encuentran un punto común de convergencia en la decisión de preferencia a la cual nos hemos referido: la decisión a favor del nivel institucional o social más cercano a los interesados.

Esclarecidas cuáles son las razones que fundan la decisión de preferencia típica del principio de subsidiariedad, así como sus implicaciones principales, corresponde entrar en mayores detalles, considerando las declinaciones del principio y los problemas a que ellas, respectivamente, dan lugar en la experiencia constitucional italiana.

\section{LA DECLINACIÓN VERTICAL Y LA DECLINACIÓN HORIZONTAL DEL PRINCIPIO}

Comenzando por el primer punto, preliminarmente puede recordarse que en Italia es ya común la distinción entre la dimensión vertical y la dimensión horizontal del principio de subsidiariedad ${ }^{18}$.

${ }^{16}$ Art. 4, apartado 3: «El ejercicio de las competencias públicas debe, de modo general, incumbir preferentemente a las autoridades más cercanas a los ciudadanos. La atribución de una competencia a otra autoridad debe tener en cuenta la amplitud o la naturaleza de la tarea o las necesidades deeficacia o economía» Sobre tal disciplina, en la literatura más reciente: SALEMA D'OLIVEIRA MARTINS, O principio da subsidiariedade em perspectiva juridico-politica, Coimbra, 2003, pp. 444 y ss.

17 Esto es puesto en relieve en el Preámbulo de la Carta, en el cual, entre otras cosas, se lee cuanto sigue: "Considerando que las Entidades locales son uno de los principales fundamentos de un régimen democrático; Considerando que el derecho de los ciudadanos a participar en la gestión de los asuntos públicos forma parte de los principios democráticos comunes a todos los Estados miembros del Consejo de Europa; Convencidos de que en este nivel local este derecho puede ser ejercido más directamente; ...».

${ }^{18}$ Se trata de una distinción utilizada ocasionalmente por la literatura en idioma alemán e introducida en Italia por el autor (Forma Stato dalla piramide all'arcipelago (relazione al convegno su "Le autonomie funzionali: le Camere di Commercio, problemi e prospettive», CNEL, 20.3.1996), en Impresa \& Stato, n. 33 [1996]). En Italia ella ha gozado de un gran reconocimiento, testimoniado del uso que hace con frecuencia la doctrina (cfr., por ejemplo: D’ATENA, A., Le Camere di commercio tra sussidiarietà verticale e sussidiarietà orizzontale, en Impresa e Stato, n. 51 (1999) (así como en D'ATENA, L'Italia verso il "federalismo". Taccuini di viaggio, Milano, 2001, pp. 390 y ss.); PASTORI, La sussidiarietà "orizzontale» alla prova dei fatti nelle recenti riforme amministrative, en RINELLA/COEN/SCARCIGLIA (editores), Sussidiarietà e ordinamenti costituzionali. Esperienze a confronto, Padova 1999; DURET, La sussidiarietà "orizzontale»: le radici e le suggestioni di un con- 
De acuerdo con las convenciones terminológicas vigentes, la primera encontraría aplicación en las relaciones entre entes territoriales de niveles distintos, mientras la segunda vendría a ser considerada en las relaciones entre el público y el privado (así como, en virtud de un pasaje de segundo grado, entre los entes territoriales y las, así llamadas, autonomías funcionales ${ }^{19}$ ).

Para coger el sentido más profundo de la distinción se debe hacer referencia a las características estructurales de las entidades que el principio de subsidiariedad, de cuando en cuando, coloca en relación.

En el caso de la subsidiariedad vertical, tales entidades son estructuralmente homogéneas. En efecto, los entes territoriales — todos los entes territoriales: desde el más pequeño municipio al Estado-, se encuentran gobernados por órganos legados al circuito de la representación política: es decir, por órganos que son expresión directa del cuerpo electoral general o de sus fracciones terri-

cetto, en Jus, 2000, p. 116; FROSINI, Profili costituzionali della sussidiarietà in senso orizzontale, en Rivista giuridica del Mezzogiorno, 2000, p. 15; POGGI, Le autonomie funzionali «tra» sussidiarietà verticale e sussidiarietà orizzontale, Milano, 2001; RESCIGNO, G.U., Principio di sussidiarietà orizzontale e diritti sociali, en Diritto pubblico, 2002, p. 5; ALBANESE, Il principio di sussidiarietà orizzontale: autonomia sociale e compiti pubblici, ibidem, 2002, p. 51; CITTADINO, Verso il federalismo: sussidiarietà orizzontale tra Stato ed autonomie, en Comuni d'Italia, 2003, p. 42; DE CARLI, Ripercussioni legislative del principio di sussidiarietà orizzontale, en Amministrare, 2004, p. 275; RAZZANO, Il Consiglio di Stato, il principio di sussidiarietà orizzontale e le imprese, en Giurisprudenza italiana, 2004; ALONSO PÉREZ, Federalismo, regionalismo e principio di sussidiarietà orizzontale, en CIMBALO/ALONSO PÉREZ, Le azioni, le strutture, le regole della collaborazione con enti confessionali. Atti del convegno, Ravenna, 25-27.9.2003, Torino 2005; MONTEMURRO, La sussidiarietà orizzontale, en Guida enti locali, 2005; ARENA, Il principio di sussidiarietà orizzontale nell'art. 118 u.c. della Costituzione en Studi in onore di Giorgio Berti, Napoli 2005; CAVALLO, Sussidiarietà orizzontale e l. n.241/1990 nel governo del territorio, in Rivista giuridica di urbanistica, 2006, p. 395; NICOLETTI, La promozione dell'attività di interesse generale degli enti privati tra sussidiarietà orizzontale e discrezionalità amministrativa, en Dir. econ., 2008, p. 767). En algunas ocasiones, la distinción puede ser encontrada también en la terminología legislativa, como lo confirma la ley 4 de diciembre de 2006, núm. 16 de la Región Umbria, la cual, en el art. 1, apartado 1, establece: «La presente legge, in attuazione degli articoli 2 e 118, comma 4, della Costituzione e degli articoli 16, comma 3 e 17 dello Statuto, disciplina i rapporti tra l'autonoma iniziativa dei cittadini singoli o associati e delle formazioni sociali e l'azione di Comuni, Province, Regione, altri Enti Locali e Autonomie funzionali, in ordine allo svolgimento di attività d'interesse generale, secondo i principi di sussidiarietà orizzontale, semplificazione e per la promozione dei principi della cittadinanza sociale»

19 Para el desarrollo del punto se renvía a D'ATENA, Lezioni di diritto costituzionale, 2. a ed., Torino, 2006, pp. 99 y ss. (así como: Le Camere di commercio tra sussidiarietà verticale e sussidiarietà orizzontale, en Impresa e Stato, cit., en D'ATENA, L'Italia verso il "federalismo»..., pp. 394 y ss.). Asimismo, hoy: Le autonomie funzionali «tra» sussidiarietà verticale e sussidiarietà orizzontale, cit., pp. 67 y ss. 
toriales, así como, frecuentemente, de órganos responsables de frente a órganos de la primera tipología. Si se tiene en cuenta el hecho de que se procede a la selección de los titulares de tales órganos a través de procesos electorales intermediados por partidos políticos, puede fácilmente constatarse que, en estos casos, la garantía asegurada por el principio es de carácter eminentemente política. En razón de esto, las decisiones que comprometen la colectividad territorial, siendo preferentemente confiadas a los órganos que las representan democráticamente, son demandadas a las mayorías políticas que las gobiernan. Esto significa que confiar al nivel de gobierno más cercano a los interesados las competencias para adoptar todas las decisiones de las que sea capaz, se traduce también - y sobretodo - en una garantía para las minorías políticas (que sean mayorías a nivel local o subestatal) con respecto a las mayorías políticas enucleadas en los niveles superiores (y sobretodo, a nivel del Estado central).

En el caso de la subsidiariedad horizontal, en cambio, las entidades que se consideran son estructuralmente heterogéneas. Esto es claramente evidente en la hipótesis en la cual el principio encuentra su expresión más inmediata: aquélla de las relaciones entre la estatalidad integralmente considerada y la sociedad civil. Pero es válida también en aquella hipótesis, derivada de esta última, y a la cual se ha hecho ya referencia: aquella de la relación entre los entes territoriales y los entes operantes en régimen de autonomía funcional. Estos últimos, en efecto, a diferencia de los primeros, no se encuentran dotados de un código genético único. Ellos, por otro lado, no se encuentran legados al circuito de la representación política (y, por ende, a la intermediación de los partidos políticos). Se trata, de hecho, de entidades en las cuales no encuentran la propia proyección institucional las poblaciones, en la totalidad indiferenciada de sus componentes (o, en otros términos: fracciones de pueblo soberano, que se expresan a través de correspondientes fracciones de cuerpo electoral general), sino que comunidades parciales. Se piense (para retomar los dos casos de autonomías funcionales expresamente previstos por la ley que, en Italia, ha canonizado la categoría ${ }^{20}$ ) a la comunidad universitaria, por un lado, y a la comunidad de las empresas de una Provincia, por otro.

Esto se refleja sobre el alcance garantísta de la subsidiariedad horizontal que, en la primera hipótesis, concierne la sociedad en cuanto tal y a los particulares que operan en ella, mientras — en la segunda — aunque si atañe, por regla general, a sujetos públicos, no se refiere a sujetos estructuralmente homogéneos a los entes territoriales sino que a sujetos exponentes de las comunidades parciales a las que nos hemos apenas referido. En esta segunda hipótesis, por tan-

${ }^{20}$ Ley núm. 59/1977 (conocida como «primera ley Bassanini»). 
to, el principio se encuentra fundamentalmente orientado a garantizar la autonomía de tales comunidades respecto de la política y sus instituciones ${ }^{21}$.

\section{LA DISCIPLINA CONSTITUCIONAL ITALIANA}

Por efecto de la reforma constitucional del año 2001, ambas declinaciones de la subsidiariedad han encontrado acogida en la Constitución italiana.

La declinación vertical se encuentra contemplada en el art. 118, apartado 1, Const. it., el cual, después de haber atribuido a los municipios la competencia administrativa general, admite desplazamientos de dichas funciones "hacia el vértice», sobre la base —entre otros- del principio de subsidiariedad.

La declinación horizontal, por su lado, encuentra reconocimiento expreso en el apartado final de la misma disposición, la cual impone a los entes territoriales de favorecer «la autónoma iniciativa de los ciudadanos, individualmente y asociados, para el desarrollo de actividades de interés general, sobre la base —en efecto- del principio de subsidiariedad».

Si se considera la novedad de estas previsiones y la complejidad del contexto regulatorio en el cual se insertan, no sorprende que hayan dado lugar a una elaboración doctrinal y jurisprudencial bastante atormentada.

\section{EL ARTÍCULO 118, APARTADO 1: EL PRINCIPIO DE SUBSIDIARIEDAD VERTICAL}

La observación vale, sobretodo, para la subsidiariedad de tipo vertical, a que se refiere el art. 118, aparatado 1, Const. it.

Mediante su previsión, la modificación constitucional ha pretendido evitar el mayor peligro al cual era expuesta la decisión de diseñar una organización elástica de las competencias administrativas. En efecto, es evidente que, una vez abandonada la técnica de la enumeración constitucional (acogida en la discipli-

${ }^{21}$ Para la aplicación de un orden de ideas parcialmente similar, puede recordarse la sentencia núm. 301/2003, en la cual la Corte Constitucional, una vez esclarecido que la actividad de las fundaciones bancarias puede reconducirse al principio de subsidiariedad (horizontal) a que se refiere el art. 118 último apartado Const. it., ha declarado la inconstitucionalidad de la norma que, en los correspondientes órganos de dirección, exigía una «preponderante y cualificada representación de los entes, diversos del Estado, a que se refiere el art. 114 de la Constitución [...]» en lugar de — como la Corte no ha dejado de aclarar- «una preponderante y cualificada representación de los entes, públicos y privados, expresivos de las realidades locales». 
na original, así como normalmente, en las constituciones federales), y una vez admitido que las competencias antes indicadas, no obstante asignadas en principio al nivel municipal, puedan ser trasladadas a los niveles superiores, habría sido muy elevado el riesgo de la total desconstitucionalización de la disciplina (por efecto del reconocimiento al legislador ordinario - sea estatal que regional- del poder de disponer a voluntad del reparto dictado por ésta, por la vía de la derogación de la débil regla de la competencia general en favor del municipio). Después de todo, ésta era exactamente el planteamiento acogido por la Comisión bicameral que ha iniciado el proceso de reforma del título $\mathrm{V}$ de la Constitución: la Bicameral «D'Alema», la cual —en los dos proyectos preparados - preveía, en cambio, que a los municipios fuera «atribuida [...] la generalidad de las funciones reglamentarias y administrativas también en aquellas materias en las cuales corresponde al Estado o a las Regiones la potestad legislativa», pero consentía que actos legislativos ordinarios pudieran derogar tal disposición, toda vez que de ella excluía «las funciones expresamente atribuidas a las Provincias, a las Regiones o al Estado, por la Constitución, por leyes constitucionales o por la ley (isic!), sin duplicación de funciones o con la identificación de las respectivas responsabilidades» ${ }^{22}$. Lo que, en último análisis, confería a la previsión de la competencia administrativa general del municipio el carácter de «disposición-manifiesto» ${ }^{23}$.

A través del principio de subsidiariedad (y la correlativa previsión de que el traslado hacia el vértice de las competencias tenga como presupuesto el «ejercicio unitario» de las mismas), la modificación constitucional ha pretendido, por ende, restringir los márgenes de apreciación demandados al legislador ordinario, creando las condiciones para el cuestionamiento jurisdiccional de sus decisiones.

La elección, sin embargo, no se encuentra exenta de problemas. Es evidente, en efecto, que la simple evocación del principio de subsidiariedad es insuficiente para otorgar al juez todos los elementos requeridos para construir la premisa mayor de su silogismo. Se piense, por ejemplo, a la dificultad que se presenta en muchos casos para establecer si para el ejercicio de una función sea, o no, necesario el «ejercicio unitario».

De aquí, un doble riesgo: que el juez decida sobreponiendo la propia valoración política a aquella del legislador o sea, que el juez deje de juzgar, asumiendo —en cambio — una actitud de deferencia respecto al legislador.

${ }^{22}$ Art. 56, apartado 2, sea del proyecto emanado el 30 de junio de 1997, que del emanado el 4 de noviembre del mismo año.

${ }^{23}$ Sobre el punto se nos permita reenviar a las reflexiones del momento realizadas por este autor, publicados en L'Italia verso il "federalismo", cit.: Il progetto licenziato dalla Bicamerale il 4 novembre 1997, ivi, 149; Alla vigilia della Bozza-Amato: le questioni sul tappeto, ibidem, pp. 156 y ss. 
La vía más eficaz para evitar tales riesgos es la procedimentalización ${ }^{24}$. Procedimientos abiertos a los sujetos interesados en el reparto son, de hecho, capaces de absolver dos funciones esenciales: por una lado, otorgan al juez elementos sintomáticos privilegiados (integrando de este modo el parámetro de la decisión y creando las condiciones para una construcción no arbitraria de la premisa mayor del silogismo judicial). Del otro lado, abren la vía a soluciones transaccionales (las cuales, al máximo, pueden encontrar expresión en acuerdos dispositivos de la repartición de las competencias).

Tal camino, inaugurado por la experiencia comunitaria ${ }^{25}$, es aquél que, con referencia al art. 118, apartado 1 Const. it., ha iniciado a recorrer la Corte Constitucional italiana, la cual, a partir de la fundamental sentencia núm. 303/2003 ha acogido con decisión la lectura procedimental del principio de subsidiariedad $^{26}$.

${ }^{24}$ Sobre el punto, especialmente, D’ATENA, Sussidiarietà e sovranità, pp. 11 y ss.; Id., In tema di presidi procedimentali del principio di sussidiarietà, en AA.VV., Sovranazionalità europea: posizioni soggettive e normazione (núm. 7 de los Quaderni del Consiglio di Stato), Torino, 2000, pp. 178 y ss.; Id., Constitución y principio de subsidiariedad, en Repertorio Aranzadi del Tribunal Constitucional, núm. 12/2001, pár. 5; Id., Subsidiarity and Division of Competencies between European Union, its Member States and their Regions, cit., p. 145; Id., Die Subsidiarität: Werte und Regeln, en BLANKENAGEL/PERNICE/SCHÜLZE-FIELITZ (editores), Verfassung im Diskurs der Welt. Liber Amicorum für Peter Häberle zum siebzigsten Geburtstag, cit., pp. 334 y ss. Asimismo, DE PASQUALE, Il principio di sussidiarietà nella Comunità europea, Napoli, 2000, pp. 87 y ss.

25 Para una información detallada se reenvía a las obras citadas en la nota precedente. La disciplina más madura sobre la materia es, como anticipado, aquella contenida en el protocolo de aplicación de los principios de subsidiariedad y proporcionalidad anexo al Tratado suscrito en Lisboa la noche entre el 18 y el 19 de octubre de 2007. Sobre los problemas aplicativos que surgen de tal disciplina (y de aquella sobre la cual ha sido modelada, establecida en el Tratado «constitucional» de Roma del 29 de octubre de 2004) se vean especialmente: INSTITUT D'ESTUDIS AUTONÒMICS, Le principe de subsidiarité dans l'Union européenne: sa consécration dans le traité instituant une constitution pour l'Europe et les perspectives pour les régions disposant de pouvoirs législatifs et, en particulier, pour leur parlement, Barcellona, 14.2.2005 (en www.issirfa.cnr.it, bajo "Osservatorio sulle Regioni > Le Regioni e l'Europa > Sussidiarietà»); NORTHERN IRELAND ASSEMBLY, The Lisbon Treaty - Application of the Principle of Subsidiarity(Briefing-Note 47/08), ibidem.

${ }^{26}$ La sentencia núm. 303/2003, cit., puede leerse en Giurisprudenza costituzionale, 2003, p. 2675, con notas de D'ATENA, L'allocazione delle funzioni amministrative in una sentenza ortopedica della Corte costituzionale, ibidem, pp. 2776 y ss.; ANZON, Flessibilità dell'ordine delle competenze legislative e collaborazione tra Stato e Regioni, ibidem, pp. 2782 y ss.; MOSCARINI, Sussidiarietà e Supremacy Clause sono davvero perfettamente equivalenti?, ibidem, pp. 2782 y ss.; GENTILINI, Dalla sussidiarietà amministrativa alla sussidiarietà legislativa, a cavallo del principio di legalità, ibidem, pp. 2805 y ss. En la misma línea, recientemente, sentencias de la Corte constitucional núms. 165/2007 y 63/2008. 


\section{Los siguientes, son los pasajes más significativos de la sentencia a este res- pecto:}

«[Il principio di sussidiarietà], con la sua incorporazione nel testo della Costituzione, ha visto mutare il proprio significato. Accanto alla primitiva dimensione statica, che si fa evidente nella tendenziale attribuzione della generalità delle funzioni amministrative ai Comuni, è resa, infatti, attiva una vocazione dinamica della sussidiarietà, che consente ad essa di operare non più come ratio ispiratrice $\mathrm{e}$ fondamento di un ordine di attribuzioni stabilite e predeterminate, ma come fattore di flessibilità di quell'ordine in vista del soddisfacimento di esigenze unitarie. [...]

Ecco dunque dove si fonda una concezione procedimentale e consensuale della sussidiarietà e dell'adeguatezza. Si comprende infatti come tali principî non possano operare quali mere formule verbali capaci con la loro sola evocazione di modificare a vantaggio della legge nazionale il riparto costituzionalmente stabilito, perché ciò equivarrebbe a negare la stessa rigidità della Costituzione. [...]

Ciò impone di annettere ai principî di sussidiarietà e adeguatezza una valenza squisitamente procedimentale, poiché l'esigenza di esercizio unitario che consente di attrarre, insieme alla funzione amministrativa, anche quella legislativa, può aspirare a superare il vaglio di legittimità costituzionale solo in presenza di una disciplina che prefiguri un iter in cui assumano il dovuto risalto le attività concertative e di coordinamento orizzontale, ovverosia le intese, che devono essere condotte in base al principio di lealtà ${ }^{27}$.

Si bien la opción en favor de la lectura procedimental del principio sea, sin dudas, posible de compartir, las orientaciones jurisprudenciales que se han ido desarrollando sobre su base justifican más de una reserva.

27 «[El principio de subsidiariedad] con su incorporación en el texto de la Constitución, ha visto cambiar el proprio significado. Junto a la primitiva dimensión estática, que se hacía evidente en la tendencial atribución de la generalidad de las funciones administrativas a los municipios, se transforma, de hecho, en activa la vocación dinámica de la subsidiariedad que le permite operar no como ratio inspiradora y fundamento de un orden de atribuciones establecidas y predeterminadas, sino como un factor de flexibilidad de este orden en vista a la satisfacción de exigencias unitarias. [...].

Es aquí, en consecuencia, donde se fundamenta una concepción procedimental y consensual de [los principios de (n.d.t.)] subsidiariedad y adecuación. Se comprende como tales principios, de hecho, no puedan operar como meras fórmulas verbales capaces con su sola evocación de modificar en beneficio de las leyes nacionales la repartición constitucionalmente establecida, porque esto equivaldría a negar la rigidez misma de la Constitución [...].

Esto impone atribuir a los principios de subsidiariedad y adecuación un valor propiamente procedimental, toda vez que la exigencia de ejercicio unitario que consiente de atraer, junto a la función administrativa, también aquella legislativa, puede aspirar a superar el análisis de legitimidad constitucional solamente en presencia de una disciplina que prestablezca un iter en el cual asuman la debida importancia las actividades de concierto e de coordinación horizontal, o sea, los acuerdos que deben ser concluidos en base al principio de lealtad». 
Esto vale, sobre todo, por el decidido favor que, principalmente en las sentencias sucesivas a la núm. 303/2003, la Corte Constitucional ha manifestado por la lectura dispositiva del principio (en lugar de aquella otra lectura de tipo sintomática). Nos referimos a la tesis según la cual el procedimiento necesario para trasladar competencias desde el nivel municipal a uno superior deba, siempre y necesariamente, surgir de un acuerdo entre el Estado y las Regiones.

Una tesis de esta clase, no solamente resulta difícil de conciliar con el absoluto silencio mantenido sobre el punto por parte de la Constitución, sino que además se coloca en tensión con el mismo principio de subsidiariedad, haciendo muy elevado el riesgo de su inactuación ${ }^{28}$. No es cuestionable, en efecto, que el principio del acuerdo, dotando de un poder de interdicción insuperable a cada uno de los sujetos involucrados en el procedimiento, haga muy onerosas las derogaciones a la regla de la competencia administrativa general del municipio. Pasando a llevar, asimismo, el principio del buen funcionamiento de la administración (sobre el cual la Corte, en años no lejanos, fundaba su propensión por los, así llamados, acuerdos $«$ débiles» ${ }^{29}$ ).

Otro aspecto no convincente del planteamiento acogido por la Corte Constitucional desde la sentencia núm. 303/2003, es la limitación de la procedimentalización a la esfera de las relaciones entre el Estado y las Regiones. En efecto, de acuerdo con su jurisprudencia, los acuerdos necesarios para realizar la atracción en subsidiariedad de las competencias administrativas deben surgir entre tales niveles de gobierno territorial. Esto resulta muy trabajosamente conciliable con la reserva a los municipios de la competencia administrativa general y con la dinámica ascendente prefigurada por la nueva disciplina constitucional. A la luz de esto resulta poco razonable dejar fuera de la participación en los acuerdos a los entes locales (o, más exactamente, sus expresiones institucionales —CAL, Conferencia Estado-Ciudad (o unificada)— y, quizás, asociativas).

El último aspecto de criticidad de la jurisprudencia constitucional en la materia se vincula a una muy compartible opción del juez de las leyes, el cual afirma que, cuando el traslado a nivel estatal de las competencias administrativas

${ }^{28}$ Sobre esta consideraciones y aquellas que siguen inmediatamente en el texto, v. D'ATENA, L'allocazione delle funzioni amministrative, cit.

${ }_{29}$ Cfr., especialmente, sentencia Corte Costitucional núm. 351/1991, en Giurisprudenza costituzionale, 1991, pp. 2806 y ss. Sobre la materia v., en general: COSTANZO, A., Collaborazione tra Stato e Regioni e buon andamento dell'amministrazione, ivi, 1988, I, pp. 815 y ss., mientras que con particular atención a los acuerdos «débiles»: D’ATENA, Sulle pretese differenze tra intese «deboli» e pareri, nei rapporti tra Stato e Regioni, ivi, 1991, pp. 3908 y ss. 
tenga como objeto funciones reconducibles a materias correspondientes a la competencia del legislador regional, a aquél debe sucederse el paralelo traslado de las competencias legislativas; en defecto del cual, puede agregarse, se encontraría comprometido el ejercicio unitario a cuya necesidad, el art. 118, apartado 1, subordina la atracción en subsidiariedad.

Como es evidente, esta opción plantea el problema de la ubicación, en la secuencia, de la participación procedimental de las Regiones. Debemos, en particular, preguntarnos si, en los casos de atracción a nivel estatal de la competencia legislativa, tal participación deba producirse antes de la adopción por parte del Estado de la ley que lo haga efectivo o, en cambio, si puede (o debe) verificarse después, del mismo modo que ésta. En el primer caso, la participación procedimental de las Regiones - y eventualmente el acuerdo en el que encuentre expresión - asumiría carácter prelegislativo, condicionando la legitimidad de la ley adoptada sobre su base; en el segundo caso, en cambio, precedería la actividad administrativa y debería constituir parte del contenido necesario de una ley adoptada unilateralmente por el Estado.

Pues bien, la orientación expresada sobre este punto por parte de la Corte se encuentra lejos de ser satisfactoria. Al respecto puede recordarse que, a las iniciales aperturas en favor de la procedimentalización prelegislativa ${ }^{30}$, se ha superpuesto un claro cierre al respecto. En la jurisprudencia más reciente, en particular, se aprecia sistemáticamente la afirmación de que los procedimientos cooperativos de tipo prelegislativo carecen de fundamento constitucional ${ }^{31}$. Una afirmación que, a pesar de su claridad, no convence. La coherencia haría necesario, de hecho, que cuando la cooperación sea invocada para justificar derogaciones al reparto de competencias legislativas ella debe preceder, y no suceder, a la actuación del legislador Estatal.

\section{EL ARTÍCULO 118 APARTADO 4: EL PRINCIPIO DE SUBSIDIARIEDAD HORIZONTAL}

No son menos complejos los problemas evocados por la disciplina constitucional de la subsidiariedad horizontal como resulta consagrada en el último apartado del artículo 118 Const. it.

\footnotetext{
30 Specialmente sentencia núm. 6/2004.

31 Cfr. las sentencias núms. 196/2004, 401/2007, 9/2008 y 371/2008.
} 


\subsection{Subsidiariedad horizontal y operaciones «in house»}

Uno de los argumentos más relevantes que plantea el principio de subsidiariedad horizontal se relaciona con el tema de los servicios públicos locales.

En particular, cabe preguntarse si, en presencia de un principio semejante, las garantías que deben ser aplicadas sean exclusivamente aquellas previstas por el derecho europeo o, en cambio, si ellas deban ser reforzadas ulteriormente.

De acuerdo con la jurisprudencia comunitaria — como es sabido- en materia de servicios públicos locales, la lógica de la libre competencia y de los principios a ella relacionados, encontrarían aplicación en la fase conclusiva de la decisión del ente público de dirigirse al mercado, mientras no operarían en la fase inicial de tal decisión: no se encontraría vedado al ente público de operar directamente, aun en presencia de favorables (o, incluso, más favorables) ofertas por parte del mercado. En efecto, la elección de la operación interna al órgano, o «in house», formando parte de las potestades de auto-organización del ente ${ }^{32}$, se encontraría sustraída a la necesidad de confrontación con el mercado. En relación con ella, el problema que viene enfrentado (y resuelto) por parte de la Corte de Justicia se refiere a los caracteres que las sociedades mixtas deben presentar para ser tomadas en consideración a los fines de la adjudicación directa ${ }^{33}$.

Pues bien, es precisamente la admisibilidad de esta zona franca (al origen de la decisión) que el art. 118 apartado final Const. it, pone en discusión.

En efecto, imponiendo tal disposición a todos los entes territoriales de favorecer «la autónoma iniciativa de los ciudadanos, individualmente o asociados, para el desarrollo de actividades de interés general» no parece conferir una simple facultad sino que establecer un deber jurídico ${ }^{34}$ que — si es tal — no puede considerarse subordinado a la decisión del ente público... de observarlo.

$\mathrm{Si}$ se acoge esta premisa, de la disposición debería concluirse que los entes territoriales indicados en la norma, en primer término, se encuentran legitimados para ejercitar las actividades de interés general mencionados en ella, en cuanto el "privado" (que debe ser entendido como un sector) no sea capaz de dar a aquéllas una adecuada satisfacción. En consecuencia, la comparación con el mercado (y con los principios de la libre competencia) no debería realizarse solamente des-

32 Especialmente Corte de Justicia Comunidades Europeas, sentencia Stadt Halle del 11.1.2005, en causa C-26/03.

${ }_{33}$ Cfr., en particolar, las sentencias: Teckal, del 19.11.1999, en causa C-107/98; Parking Brixen del 13.10.2005, en causa C-458/03; Stadt Halle, cit.; Carbotermo del 11.5.2006, en causa C-340/04.

${ }^{34}$ Análogamente: RESCIGNO, G. U., Principio di susdiarietà orizzontale e diritti sociali en Diritto pubblico, 2002, pp. 29 y ss. 
pués que el ente público ha decidido no intervenir directamente sino, también, con anterioridad: es razonable entender que la actuación directa se justifica exclusivamente en el respeto de la lógica de la subsidiariedad ${ }^{35}$.

\subsection{Las lecturas desvalorizadoras del art. 118 apartado 4: crítica}

Es, por otro lado, necesario señalar que esta interpretación no es pacífica en la literatura. De hecho, no se han hecho esperar lecturas desvalorizadoras del art. 118, aparatado final, según las cuales la disposición no sustraería ningún ámbito a la posibilidad de intervención de los sujetos públicos mencionados por la norma (Estado, Regiones, Ciudades Metropolitanas, Provincias y Municipios), sino que, al máximo, empeñaría a dichos sujetos públicos a ejercitar las propias funciones en modo de favorecer la participación de los privados. No tendría incidencia sobre el «si» sino que sobre el «en qué modo» debe desarrollarse la intervención del sector público ${ }^{36}$.

Sin embargo, la opinión no parece convincente, ni convincentes parecen ser los argumentos comúnmente utilizados para sostenerla.

Esto es válido, en primer término, para el argumento «topográfico», según el cual un principio de un alcance tan revolucionario habría debido encontrar la propia posición en otro lugar de la Constitución (no, al menos, en la disposición dedicada a las funciones administrativas, sino que en el ámbito de los principios fundamentales que anteceden la Parte Primera) ${ }^{37}$. Si bien, de hecho, y prescindiendo de la no insuperable fuerza de argumentaciones de esta naturaleza, no

35 Muy adecuados al respecto son algunos pasajes del acto de señalación adoptado por la Autoridad de Garantía de la Competencia y del Mercado el 28 de diciembre de 2006 (AS 375 - Affidamento di servizi pubblici locali aventi rilevanza economica secondo modalità c.d. in house e ad alcuni contenuti della legge delega in materia di tali servizi, en B.U. núm. 50 del 2.1 2007, p. 74), en el cual — con referencia al proyecto de delegación legislativa en materia de servicios públicos locales de la pasada legislatura (AS 772) — se lee cuanto sigue: «In particolare, andrebbe indicato il principio che l'affidamento diretto risulta giustificato solamente quando non è possibile individuare una migliore soluzione di mercato, secondo un principio di sussidiarietà che limiti l'intervento pubblico a quelle situazioni in cui non sia possibile o conveniente l'offerta dei servizi da parte di imprese individuate secondo meccanismi di mercato». En la misma línea, significativamente: Consiglio di Stato, sez. V, 25 agosto 2008, núm. 4080. Mayores informaciones sobre que la preferencia en favor del mercado no opere solamente cuando éste sea capaz de asegurar condiciones más favorables, sino que también en caso de igualdad de condiciones, véase, infra, núm. 7.3.

${ }^{36}$ Así, especialmente, MASSA PINTO, Il principio di sussidiarietà. Profili storici e costituzionali, Napoli, 2003, pp. 135 y ss.

${ }^{37}$ MASSA PINTO, Il principio di sussidiarietà, cit., p. 148. 
puede olvidarse que la reforma del 2001, teniendo como objeto únicamente el título V de la Constitución, no disponía de una sedes materiae diversa. Por otra parte, la situación es similar para otras disposiciones que habrían podido encontrar una colocación más adecuada. Por ejemplo, piénsese en el apartado 1 del art. 117 Const. it. el cual, no refiriéndose al reparto de las competencia, sino que al ejercicio de las funciones legislativas y a los límites generales que le han sido trazados, no resulta felizmente incorporado en el artículo que distribuye la potestad normativa entre los diversos niveles territoriales de gobierno.

En sentido opuesto a la tesis sostenida no parece ni siquiera que se pueda invocar el tenor literal de la disposición.

De hecho, aunque si no se considerara que la forma verbal «favorecen» evoque la Vorrangentscheidung que constituye la médula del principio de subsidiariedad (es decir, la "decisión de preferencia» a favor del ámbito más cercano, en la especie, del «privado») $)^{38}$, no podría ignorarse la frase que cierra el apartado. Ella, trayendo a colación expresamente el "principio de subsidiariedad» («favorecen [...] sobre la base del principio de subsidiariedad»), esclarece, más allá de toda duda, que el modo en el cual el «favorecer» por parte de los entes territoriales debe encontrar su expresión sea (deba ser) aquél que resulta típico de la subsidiariedad $^{39}$. Y transforma, de esta manera, en evidente que el favor predicado por la norma debe traducirse, por un lado, en la preferencia acordada a la sociedad civil, con relación a las actividades de interés general que es capaz de desarrollar y llevar a cabo y, por otro, en el rol subsidiario que el ente público, que se encuentra llamado a hacer frente a las eventuales incapacidades de los ciudadanos individuales o asociados.

Es significativo que quien niega estas implicaciones de la norma se funde en una concepción revisada y corregida — se si nos permiten estas expresiones- del principio de subsidiariedad, del cual borra la más profunda connotación estructural.

En esta línea se pone — por ejemplo- una decisión adoptada por el Tribunal Administrativo Regional de La Cerdeña en el $2007^{40}$, la cual rompe el prin-

38 En sentido contrario parece expresarse, por ejemplo, POLITO, Art. 118 u.c. della Costituzione, Un approfondimento sul "favoriscono», en el sitio web de Astrid (http://www.astrid-online.it), passim, especialmente pp. 21 y ss.

39 Muy exactas sobre el punto, las observaciones de RESCIGNO, G.U., Principio di sussidiarietà orizzontale e diritti sociali, cit., p. 30 .

40 Tribunale Amministrativo Regionale (TAR) della Sardegna, sez. I, 21.12.2007 núm. 2407, criticado por DI GIACOMO RUSSO, TAR Sardegna: l'affidamento «in house» alla luce del Regolamento CE n. 1370/2007 e della sentenza del 17 luglio 2008 (causa C-371/05) della Corte di Giustizia CE, en Foro amministrativo TAR, 2008, pp. 2254 y ss., especialmente pp. 2256 y ss. 
cipio en dos, afirmando que en el art. 118 último apartado, los aspectos negativo y positivo del principio de subsidiariedad no sean complementarios, sino que se presentan en modo separado. Esto permite al juez deducir de la norma «un deber de intervención de los poderes públicos cuando los individuos o las fuerzas de la sociedad no tengan la capacidad de proveer por sí mismos a las propias necesidades», pero no un "deber de abstención [...] en el caso que las fuerzas individuales y de la sociedad sean capaces de satisfacer sus propias necesidades en modo autónomo» ${ }^{41}$.

La incompatibilidad de una configuración similar con la lógica de la subsidiariedad parece fuera de discusión. Toda la elaboración que el principio tiene a sus espaldas gira en torno a la idea que la intervención del nivel superior (en la especie, el poder público) no sea siempre y en todo caso justificada, sino que lo sea sólo cuando se encuentra dirigida a obviar la inadecuación del nivel más cercano (en la especie, del "privado»). Se trata, en otros términos, de un subsidium destinado a realizarse, cuando el ámbito a favor del cual opera la decisión de preferencia no baste (retomando las palabras pronunciadas en el ámbito de la Asamblea Constituyente por Giuseppe Dossetti, más de sesenta años atrás); y sea, en consecuencia, desprovisto de toda justificación cuando éste, en cambio, resulte suficiente ${ }^{42}$.

\subsection{La lectura "fuerte» del art. 118 apartado final: a) con referencia a las relaciones público-privadas (analogía con la disciplina de numerosas Gemeindeordnungen alemanas)}

Si se desarrollan con coherencia estas premisas (y si, de la misma manera, se lee el apartado final del art. 118 Const. it.), resulta razonablemente sostenible

${ }^{41}$ Análogamente, en doctrina, ya: ALBANESE, Il principio di sussidiarietà orizzontale: autonomia sociale e compiti pubblici en Diritto pubblico 2002, p. 77.

42 Sobre el punto v. por ejemplo, en la literatura más reciente: RULAND, Das «Soziale» im Spannungsfeld von Solidaritàt und Subsidiaritàt, ponencia en el Congreso del Forschungsnetzwerk Alterssicherung sobre "Das Soziale in der Alterssicherung», Erkner, 1-2-12.2005, quien pone en evidencia la inseparabilidad del perfil negativo del perfil positivo de la subsidiariedad: «Negativ sei der Staat verpflichtet, alles, was die Individuen und Subsysteme leisten können, diesen nicht zu entziehen. Positiv sei er gehalten, alles zur Förderung seiner Glieder zu tun und nur dann Hilfe zu leisten, wenn sie in deren Interesse erforderlich ist». Reflexiones de notable interés se leen sobre el punto en LOO GUTIÉRREZ, M., La disciplina constitucional del principio de subsidiariedad en Italia y Chile en Revista de Derecho de la Pontificia Universidad Católica de Valparaíso, 2009, pp. 418 y ss., quien, destacando la inseparable conexión entre los dos perfiles, propone una interpretación no literal del art. 19 núm. 21 de la Const. chilena. 
que en Italia se encuentre vigente una regla análoga a aquella frecuentemente enunciada por las Gemeindeordnungen alemanas: la regla en virtud de la cual los entes territoriales pueden asumir directamente la gestión de actividades empresariales sólo si (y en cuanto) sean capaces de hacerlo en condiciones más favorables que aquellas ofrecidas por el mercado ${ }^{43}$.

Por ejemplo, es significativa al respecto la disciplina dictada por la $G e-$ meindeordnung bávara (en la versión publicada el 2 de agosto de 1998 y modificada el 20 de diciembre de 2007) cuyo art. 87, apartado 1, subordina la creación, la adquisición o la significativa ampliación de una empresa por parte del Municipio a la condición que la finalidad no sea, ni pueda ser conseguida por otros sujetos en iguales términos de calidad y economicidad. Formulaciones prácticamente idénticas se encuentran — por ejemplo_ en la Gemeindeordnung de la Renania-Palatinado, en la versión del 31 de enero de 1994, modificada el 28 de mayo de 2008 ( $\$ 85$ apartado 1) y en la Gemeindeordnung del Land Hessen, en la versión del 1 de abril de 2005 (\$121 apartado 1). Distinta es la «disposición» pero análoga la "norma» (según la terminología utilizada por Vezio Crisafulli) del $\$ 100$ apartado 3, de la Gemeindeordung del Brandenburgo (en la versión publicada el 10 de octubre de 2001 y modificada el 22 de junio de 2005) en la cual se lee: «El municipio debe preocuparse en el interés y la economicidad de la gestión, que a los operadores privados sean encomendadas las actividades que ellos pueden desarrollar a costos idénticos o más bajos y con garantía de calidad y confiabilidad al menos idénticas, en cuanto ello sea compatible con el interés público».

La tesis aquí sostenida en orden a que el art. 118, último apartado Const. it., establezca una disciplina análoga a aquellas que hemos apena pasado en reseña, encuentra su fundamento en la decisión de preferencia enunciada por la norma. De hecho, si tal decisión tiene algún sentido, de ella no puede sino deducirse dos corolarios:

- que la elección de proceder a la operación «in house» no se encuentra eximida del respeto del principio de subsidiariedad.

43 En la literatura italiana, un orden de ideas, en alguna medidas análogo, no casualmente ligado al principio de subsidiariedad se desarrolló, también, antes de la constitucionalización del mismo por parte de la ley constitucional núm. 3/2001. Se vean, de hecho: PACE, Problematica delle libertà costituzionali. Parte speciale, II edic., Padova, 1992, pp. 479 y ss., quien, en el cuadro constitucional entonces vigente, admitía, más bien, que la ley podía reconocer la iniciativa económica también a los entes públicos, considerando, sin embargo, indispensable que tal reconomiento no perjudicara la libertad reconocida a los privados. 
- que dicha decisión no solamente sea inhibida cuando las condiciones ofrecidas por el mercado sean más ventajosas que aquellas que la empresa pública (o participada) sea capaz de garantizar, sino que también —se preste atención- en igualdad de condiciones ${ }^{44}$.

Todo, obviamente, siempre que el servicio, por su naturaleza, no haga imprescindible la intervención del sujeto público, en consideración a las garantías que solamente éste puede asegurar (sólo para dar un ejemplo, se piense a la garantía de imparcialidad de las fuerzas del orden). En efecto, se encuentra fuera de dudas que, en presencia de exigencias de garantías de esta clase el "privado» -usando nuevamente las palabras de Giuseppe Dossetti- no basta.

A la luz de cuando antecede, debe saludarse con favor la reciente reforma a la normativa que regula los servicios públicos locales de relevancia económica ${ }^{45}$, la cual, en actuación del art. 118, último apartado Const. it.:

a) por un lado, prevé que la «regla» se encuentre representada por el encargo ordinario de ellos a favor del mercado ${ }^{46}$;

${ }^{44} \mathrm{El}$ punto es puesto en su justa relevancia por el mayor estudio sobre el argumento: ISENSEE, Subsidiaritätsprinzip und Verfassungsrecht. Eine Studie über das Regulativ des Verhältnisses von Staat und Gesellschaft, Berlin, 1968, pp. 75 y ss., en el cual se evidencia que no corresponden a la lógica de la subsidiariedad las Gemeindeordunungen que subordinan la intervención del municipio a la falta de ofertas más favorables por parte del mercado. (En este sentido, por ejemplo, el art. 102, apartado 1, núm. 3 de la Gemeindeordnung del Baden-Württemberg, en la edición del 24 de julio de 2000, modificada el 28 de mayo de 2003). A juicio de ISENSEE — de hecho- la decisión de preferencia que se encuentra a la base del principio de subsidiariedad exige que sean los entes públicos a deber asegurar condiciones más favorables para que puedan ser preferidos: en caso de igualdad de condiciones, la elección debe recaer sobre los operadores privados. Adhesivamente, en la doctrina italiana: D'ATENA, Costituzione e principio di sussidiarietà en Quaderni costituzionali, 2001, pp. 18 y ss.

45 Art. 23-bis decreto ley núm. 112/2008, convertido en ley núm. 133/2008, como modificado por el art. 15 decreto ley núm. 135/2009, convertido en ley núm. 166/2009.

46 Se trata - ex art. 23-bis cit., comma 2- de la asignación de la gestión del servicio a empresas privadas o sociedades mixtas (a condición que la selección del socio se realice mediante procedimientos competitivos de evidencia pública). Este es el tenor literal del apartado: «Il conferimento della gestione dei servizi pubblici locali avviene, in via ordinaria: a) a favore di imprenditori o di società in qualunque forma costituite individuati mediante procedure competitive ad evidenza pubblica, nel rispetto dei principi del Trattato che istituisce la Comunità europea e dei principi generali relativi ai contratti pubblici e, in particolare, dei principi di economicità, efficacia, imparzialità, trasparenza, adeguata pubblicità, non discriminazione, parità di trattamento, mutuo riconoscimento e proporzionalità; b) a società a partecipazione mista pubblica e privata, a condizione che la selezione del socio avvenga mediante procedure competitive ad evidenza pubblica, nel rispetto dei principi di cui alla lettera a), le quali abbiano ad oggetto, al tempo stesso, la 
b) por otro lado, consiente - en vía derogatoria - el encargo mediante gestión «in house», mas sólo en hipótesis excepcionales que deben ser específicamente motivadas sobre la base de una verificación que debe ser sometida a la Autoridad de Garantía de la Competencia y del Mercado, llamada a emitir un parecer preventivo ${ }^{47}$.

\subsection{Sigue: b) con referencia a las relaciones entre las autonomías territoriales $y$ las autonomias funcionales}

La segunda implicación de la lectura aquí expuesta se relaciona con los entes con autonomía funcional (cuya mención expresa fue inopinadamente cancelada en la última versión de la reforma del título V Const. $)^{48}$. Los cuales, sin embargo, son contemplados en el art. 118, apartado final, bajo un doble perfil.

En primer lugar, ellos pueden ser considerados en cuanto estructuras asociativas de los sujetos privados. De hecho, aun siendo, en general, configurados como personas jurídicas de derecho público, se encuentran provistos de un substrato de tipo asociativo, siendo gobernados por órganos representativos de las comunidades parciales a las cuales se refieren. Para percatarse de esto, es suficiente recordar las Cámaras de Comercio, los Consorcios de Saneamiento, los Órdenes profesionales.

qualità di socio e l'attribuzione di specifici compiti operativi connessi alla gestione del servizio e che al socio sia attribuita una partecipazione non inferiore al 40 per cento".

47 Tal disciplina se contiene en los apartados 3 y 4 del cit. art. 23-bis, los cuales, respectivamente prescriben: «[3] In deroga alle modalità di affidamento ordinario di cui al comma 2, per situazioni eccezionali che, a causa di peculiari caratteristiche economiche, sociali, ambientali e geomorfologiche del contesto territoriale di riferimento, non permettono un efficace e utile ricorso al mercato, l'affidamento può avvenire a favore di società a capitale interamente pubblico, partecipata dall'ente locale, che abbia i requisiti richiesti dall'ordinamento comunitario per la gestione cosiddetta «in house» e, comunque, nel rispetto dei principi della disciplina comunitaria in materia di controllo analogo sulla società e di prevalenza dell'attività svolta dalla stessa con l'ente o gli enti pubblici che la controllano. [4] Nei casi di cui al comma 3, l'ente affidante deve dare adeguata pubblicità alla scelta, motivandola in base ad un'analisi del mercato e contestualmente trasmettere una relazione contenente gli esiti della predetta verifica all'Autorità garante della concorrenza e del mercato per l'espressione di un parere preventivo, da rendere entro sessanta giorni dalla ricezione della predetta relazione. Decorso il termine, il parere, se non reso, si intende espresso in senso favorevole.» Corresponde añadir que, en virtud del apartado 4-bis de la disposición, el deber de traslado del informe a la Autoridad de Garantía no opera siempre, sino que solo si se superan ciertos umbrales que deben ser determinados mediante acto reglamentario.

48 Sobre la erosión que, en el camino de la reforma constitucional, han tenido las referencias al principio de subsidiariedad y aquel de las autonomías funcionales, se nos permita el reenvío a D’ATENA, Costituzione e principio di sussidiarietà, cit., pp. 31 y ss. 
En presencia de tal requisito, no existen razones para negar que tales entidades puedan ser consideradas una especie dentro del género privados «asociados» contemplada en el art. 118, apartado final Const. it.

Tampoco parece que a tal conclusión se pueda oponer como argumento la subjetividad de carácter público de la cual gozan.

En primer término, porque una limitación de esa especie no es, en algún modo, deducible del tenor literal de la norma constitucional la cual, en una manera amplísima, hace referencia a las estructuras asociativas sin realizar distinciones entre ellas; por ende, acogiéndolas en toda la variedad tipológica que ellas pueden presentar.

Además, se debe considerar que la personalidad jurídica de derecho público no anula la sustancia asociativa que constituye su sustrato sino que, por el contrario, se suma a ella.

Precisamente ésta es la razón por la cual, por ejemplo, se reconoce a los consorcios de saneamiento - retomando palabras expresadas por la Corte Constitucional en una fundamental sentencia (núm. 326/1998) — una doble faz: una asociativa y otra institucional.

$\mathrm{Al}$ respecto, en la sentencia apenas indicada se lee:

«[... ] i consorzi hanno un doppio volto e una duplice funzione. Da un lato, essi sono espressione, sia pure legislativamente disciplinata e resa obbligatoria, degli interessi dei proprietari dei fondi coinvolti nella attività di bonifica o che da essa traggono beneficio: strumenti normativamente previsti, attraverso i quali i proprietari adempiono ad obblighi su di loro gravanti in relazione alle opere di bonifica e si ripartiscono fra loro gli oneri relativi. Pertanto, coerentemente, i consorzi sono amministrati da organi espressi dagli stessi proprietari [...]. Dall'altro lato, essi si configurano come soggetti pubblici titolari o partecipi di funzioni amministrative, in forza di legge o di concessione dell'autorità statale (ora regionale) $)^{49}$.

En presencia de esta "faz» asociativa, la pretensión de que la garantía ofrecida por el art. 118, último apartado Const. it., no opere en favor de las autonomías funcionales que de ella gocen, resulta carente de un fundamento serio.

49 «[...] los consorcios tienen una doble faz y una doble función. Por un lado, ellos son expresión, aun cuando legislativamente disciplinada y hecha obligatoria, de los intereses de los propietarios de los terrenos involucrados en la actividad de saneamiento o que de ella obtienen beneficio: instrumentos normativamente previstos, a través de los cuales los propietarios cumplen deberes que les incumben en relación con las obras de saneamiento y reparten entre ellos los relativos costos. Por lo tanto, coherentemente, los consorcios son administrados por órganos originados en los mismos propietarios [...]. Por otro lado, ellos se configuran como sujetos públicos titulares o partícipes de una función administrativa, por virtud de la ley o de concesión de la autoridad estatal (ahora, regional)». 
Sin embargo, no podemos detenernos en este punto.

De hecho, como se anticipó, las autonomías funcionales se encuentran atraídas hacia la esfera operativa de la previsión constitucional del art. 118, último apartado Const. it., también bajo un segundo perfil: en su calidad de entes públicos que no solamente se colocan en la frontera que separa los poderes públicos de la sociedad civil, sino que son expresión exactamente del «trozo» de sociedad civil a la cual se encuentra destinada su acción. Ellas, dotando de una proyección institucional a las comunidades parciales que, respectivamente, constituyen su substrato social, se configuran como instrumentos de autogobierno de las mismas. En esta línea se coloca una metáfora utilizada en Alemania para las Cámaras de Comercio, las cuales vienen calificadas como «Municipios de la Economía» (Wirtschaftsrathäuser).

El punto es de gran importancia.

En efecto, resulta evidente que, si los entes de autonomía funcional son expresión de las comunidades parciales a las cuales se dirige su acción, ellos, respecto a éstas son las instancias institucionales "más cercanas»: funcionalmente más cercanas, para usar las palabras de la ley núm. 59/1997, citada anteriormente (art. 4, apartado 3, letra a) $)^{50}$.

Es, por ende, razonable sostener que, en base al principio de subsidiariedad, precisamente a aquellos órganos debe recurrirse cuando el perseguimiento de los resultados requiere el empleo de una instrumentación de tipo publicística.

Sobre estas bases no es posible sustraerse a la conclusión de que el art. 118, apartado final Const. it., no tutela exclusivamente las expresiones privatísticas de la sociedad civil, sino también sus expresiones publicísticas constituidas, precisamente, por los entes de autonomía funcional.

De la tutela consagrada por la norma se deben deducir al menos dos corolarios:

a) una garantía de existencia a favor de los entes de autonomía funcional, los cuales deben ser tutelados en relación con el conjunto de los entes territoriales;

b) un principio de tutela de las funciones de los mismos actualmente ejercitadas, las cuales -importando el desarrollo de actividades de interés general por parte de entes exponentes de las comunidades (parciales) directamente interesadas, constituyen una (anticipada) actuación del principio de subsidiariedad horizontal.

${ }^{50} \mathrm{La}$ tesis y las deducciones reportadas en el texto pertenecen al autor. Se vea: D'ATENA, Le autonomie funzionali, tra riforma del titolo Ve riforma della riforma en Le Regioni dopo il Bang. Il viaggio continua, Milano, 2005, pp. 268 y ss. 
En relación específica con el segundo corolario, debe destacarse que él encuentra importantes aplicaciones en la legislación nacional.

En materia deben recordarse las normas que, en aplicación de la, así llamada, "prohibición de paso atrás» (Rückschrittverbot), dejan a salvo las tareas ya desarrolladas por los entes de autonomía funcional, las cuales parten del presupuesto que, retiradas respecto a la actual estructura competencial (mediante la traslación a entes públicos territoriales de funciones que actualmente corresponden a aquéllos) contrastaría con el principio de subsidiariedad horizontal.

Resulta emblemático en materia el art. 7, apartado 1, de la principal ley de actuación del Título V de la Constitución: la ley núm. 131/2003 (la ya citada ley "La Loggia»), la cual prevé expresamente que la redistribución de las funciones administrativas deba realizarse «en el respeto, también a los fines de la asignación de adicionales funciones, de las atribuciones de los entes de autonomía funcional, asimismo en los sectores relativos a la promoción del desarrollo económico y de la gestión de servicios».

En la misma línea debe considerarse una reciente norma en materia de consorcios de saneamiento: el art. 27 del Decreto ley núm., 248/2007, convertido con modificaciones en la ley núm. 31/2008. La norma ha previsto, más bien, la «reordenación, también mediante incorporación o eventual supresión de individuales (si preste atención: individuales) consorcios, de consorcios de saneamiento y de mejoramiento terrario a que se refiere el capítulo I del título $\mathrm{V}$ del real decreto de 13 de febrero de 1933, núm. 215 y sus sucesivas modificaciones», sino que ha hecho expresa excepción de las atribuciones actualmente asignadas a tales entes («Se exceptúan las funciones y las tareas actualmente desarrolladas por los mismos consorcios»).

Title:

DIMENSIONS OF SUBSIDIARITY IN ITALIAN CONSTITUTIONAL LAW

\section{Summary}

1. THE ETHICAL-POLITICAL DIMENSINON AND THE LEGAL-CONSTITUTIONAL DIMENSION. 2. THE DECISION OF PREFERENCE FOR THE CLOSEST LEVEL. 3. THE ROOTS OF PREFERENCE. 4. THE VERTICAL AND HORIZONTAL DIMENSIONS OF THE PRINCIPLE. 5. THE ITALIAN CONSTITUTIONAL REGULATION. 6. ARTICLE 118, SECTION 1: THE PRINCIPLE OF VERTICAL SUBSIDIARITY. 7. ARTICLE 118, SECTION 4: THE PRINCIPLE OF HORIZON- 
TAL SUBSIDIARITY. 7.1. Horizontal subsidiarity and in house operations. 7.2. The devaluing approaches to Article 118, section 4: criticism. 7.3. The "forceful» reading of Article 118, final section: with reference to public-private relationships (analogy with the regulation of the numerous german Gemeindeordnungen). 7.4. Follows: b) With reference to relationships between territorial autonomies and functional autonomies.

\title{
Resumen
}

Tras repasar las dimensiones ético-política y jurídico-constitucional del principio de subsidiariedad, así como las raíces de la subsidiariedad (doctrina social de la Iglesia, tradición liberal, y reflexión europea sobre el federalismo), el autor se centra en las contradicciones que ha generado tal principio. En efecto, tomando en consideración los ejemplos del federalismo en Estados Unidos de América y el proceso de integración europea hasta el Tratado de Maastricht, el autor subraya que el juego de la subsidiariedad no siempre ha conllevado dar prioridad al nivel más cercano, lo que ha incluido posiciones «anti-subsidiariedad». En este sentido, el ensayo ilustra esas contradicciones a través de la experiencia constitucional italiana con apoyo en las dimensiones vertical (relaciones entre los diversos niveles territoriales) y horizontal (relaciones entre lo público y lo privado) del principio de subsidiaridad establecidas en el artículo 118 de la Constitución italiana tras la reforma de 2001. El autor concluye (teniendo en cuenta asimismo la experiencia constitucional comparada, en especial la alemana) que la base constitucional italiana ha resultado ambigua, en la medida en que tanto el desarrollo legislativo como el jurisprudencial (Corte Constitucional y Tribunales Ordinarios) ha dado lugar a fluctuantes enfoques «devaluadores» $\mathrm{y}$ «fuertes» de la subsidiariedad.

\begin{abstract}
After reviewing the ethical-political and legal-constitutional dimensions of the principle of subsidiarity, as well as the roots of subsidiarity (the Church's social doctrine, liberal tradition, and European reflection on federalism), the author focuses on the contradictions emerging from such a principle. Indeed, taking into account the examples of federalism in the United States and the European integration process until the Treaty of Maastricht, the author stresses that the game of subsidiarity has not always led to give priority to the nearest level, including "anti-subsidiarity» positions. In this sense, the paper illustrates these contradictions through the Italian constitutional experience in the light of the vertical dimension (relationships between different te-
\end{abstract}


rritorial levels) and the horizontal dimension (relationships between public and private) of the subsidiarity principle laid down in Article 118 the Italian constitution after the 2001 reform. The author concludes (also taking into account comparative constitutional experience, especially the German one) that the Italian Constitutional legal basis has been ambiguous, in so far as both the legislation and the case-law (from the Constitutional Court and Ordinary Courts) has led to fluctuating «undervalued» and «strong» approaches of subsidiarity.

\section{Palabras clave}

Subsidiariedad vertical y horizontal, federalismo, integración europea, descentralización, igualdad territorial, tensiones normativas y jurisprudenciales en el ordenamiento jurídico italiano.

\section{Key word}

Vertical and horizontal subsidiarity, federalism, European integration, devolution, territorial equality, legal and jurisprudential tensions within the Italian legal system. 